NASA

Technical Memorandum 106103

AIAA-93-2298
Army Research Laboratory Memorandum Report ARL-TR-11

\title{
Evaluation of a Vibration Diagnostic System for the Detection of Spur Gear Pitting Failures
}

Dennis P. Townsend and James J. Zakrajsek

Lewis Research Center

Cleveland, Ohio

Prepared for the

29th Joint Propulsion Conference and Exhibit

cosponsored by the AIAA, SAE, ASME, and ASEE

Monterey, California, June 28-30, 1993 


\title{
EVALUATION OF A VIBRATION DIAGNOSTIC SYSTEM FOR THE DETECTION
}

\section{OF SPUR GEAR PITTING FAILURES}

\author{
Dennis P. Townsend and James J. Zakrajsek \\ National Aeronautics and Space Administration \\ Lewis Research Center \\ Cleveland, Ohio 44135
}

\begin{abstract}
$\underline{\text { Abstract }}$
A vibration diagnostic system was used to detect spur gear surface pitting fatigue in a closed-loop spur gear fatigue test rig. The diagnostic system, comprising a personal computer with an analog-to-digital conversion board, a diagnostic system unit, and software, uses timesynchronous averaging of the vibration signal to produce a vibration image of each tooth on any gear in a transmission. Several parameters were analyzed including gear pair stresswave and raw baseband vibration, kurtosis, peak ratios, and others. The system provides limits for the various parameters and gives a warning when the limits are exceeded. Several spur gear tests were conducted with this system and vibration data analyzed at 5 -min intervals. The results presented herein show that the system is fairly effective at detecting spur gear tooth surface fatigue pitting failures.
\end{abstract}

\section{Introduction}

Aircraft gearbox failure can be a serious problem on aircraft such as turboprops, geared fans, and helicopters. Many times transmissions must be overhauled at a given life even when no failures have occurred simply because operating times set prior to overhaul have been met. If these transmissions had considerable life remaining, they could have been operated for a longer time provided a good failure detection system were available. Several methods of failure detection for aircraft gearboxes have been in use for several years with limited success. Chip detection will sometimes give an indication of failure if there are enough chips to reach the chip detector without becoming trapped in the system. SOAP (Spectrometric Oil Analysis Program) has been used for failure detection for several years ${ }^{1}$ with only some success. Unfortunately, SOAP will not give any indication of failure when an improved filtering system is used, which is typical of most aircraft lube systems operating today.

Failure detection methods using spectrum analysis of vibration or noise signals have also been used with limited success. These spectrum analysis methods require an evaluation of the various harmonics and sideband frequencies to find a particular type of failure.

Recent vibration-based failure detection methods have been developed by using time-synchronous averaging of the gear mesh vibration signal. ${ }^{2-3}$ The vibration signal of a particular gear is found by time averaging the raw vibration signal with a pulse signal synchronized to the rotation of the gear being analyzed. With this method, the random vibration, which is noncoincident with the rotation of the gear, will average out to a very low residual value leaving only the vibration resulting from the gear being analyzed. This time-averaged vibration signal usually depicts the meshing pulse for each tooth on the gear over one complete revolution.

Several parameters are calculated from the timeaveraged signal to find failure conditions such as fatigue spalls and cracks. In addition, the shape and amplitude of each gear-tooth pulse is evaluated to determine whether a change has occurred over a given time period.

The objective of the research reported herein was to determine the performance of recently developed vibration-based detection methods as they were applied to experimental data. The vibration data were obtained from a gear fatigue test rig at NASA Lewis Research Center by running several test gears until a fatigue failure occurred. The failure modes of test gears used in this program ranged from moderate pitting on two teeth in one test to spalling over several teeth in another test. 


\section{Vibration Data}

The gearbox case has several vibration modes that affect the gear vibration signal. Accelerometer vibration measurements were taken at several locations on the gearbox to find the best vibration signal. The best location was found to be on the seal plate next to the bearing and adjacent to the test gear along the line of action of the gear pair. A more detailed discussion of the gearbox vibration is given in Ref. 4 . Figure 1 is a spectrum of the test gearbox showing the various vibration frequencies; several peaks appear much stronger than the gear mesh peak. These peaks represent vibration modes of the gearbox structure. These modes, in turn, complicate the task of monitoring the condition of the gears. Figure 2(a) is a typical envelope, or the amplitude modulation function, of the time-averaged vibration signal for the NASA Lewis test gearbox, and Fig. 2(b) is a similar plot for a helicopter gearbox, where the gear mesh frequency peaks are sharper.

\section{Gear Diagnostic System}

A commercial gear diagnostic system was used in this research program. The system consists of a personal computer with an analog-to-digital board installed, a signal-conditioning system, and a software package. A schematic of the system is shown in Fig. 3. The signalconditioning system includes a computer-controlled tracking filter, computer-controlled analog signal conditioning, a pulse rate multiplier/divider, and interfacing electronics. The software automatically sets and monitors the analog signal-conditioning circuitry, performs the analysis, and provides monitor displays of individual gear-tooth vibration images. It also displays gear condition status and issues alarms when appropriate. The software can display current and past data in a variety of formats. Figure 4 is a flowchart of the system.

High-pass and low-pass filters are used in front of the system to remove the vibration frequencies above and below a user set condition. The filter for this test program was set to remove frequencies below $80 \mathrm{kHz}$ and above $120 \mathrm{kHz}$.

The gear diagnostic system uses a number of techniques to extract the condition of the gears from the raw vibration signal. The raw signal is time-synchronous averaged over the meshing cycle of each tooth on the gear being monitored. A proximity probe was used to detect the passage of each gear tooth, with the resulting time pulse used for the averaging process. Timesynchronous averaging is used to filter out the parts of the vibration signal not coincident with the meshing cycle of the gear being monitored.
A time-averaged signal was produced for two areas of interest: the low-frequency band, or baseband vibration, and the high-frequency band. The baseband vibration in this application is the portion of the signal up to $10 \mathrm{kHz}$, which includes the primary meshing frequency $(4.7 \mathrm{kHz})$ and its first harmonic $(9.4 \mathrm{~Hz})$. The baseband vibration was demodulated about the meshing frequency, and the amplitude modulation function, or envelope, was then constructed. The envelope of the baseband vibration depicts the vibration pattern of each tooth on the gear by using the low-frequency components of the signal. Figure 5(a) shows an example of a baseband envelope plot. The high-frequency band in this application is the portion of the signal between 80 and $120 \mathrm{kHz}$. This high-frequency band was demodulated about a harmonic of the meshing frequency and the amplitude modulation function was then constructed. The envelope of the high-frequency band is also known in this system as the gear pair stresswave. The stresswave depicts the vibration pattern of each tooth on the gear by using the high-frequency components of the vibration signal. In many cases, the resolution of the tooth-meshing pattern is considerably better in the stresswave than that in the baseband envelope. This is due to the decreased effect of the vibration transfer path dynamics at higher frequencies. Figure 5(b) shows an example of a stresswave plot.

A number of signal-processing techniques were applied to the baseband envelope and stresswave to obtain the condition of the gears. Each of these methods, designated M1 to M11, is designed to detect specific defects in the meshing pattern that correspond to various gear-tooth faults. The M9 method, for example, is the normalized kurtosis of the baseband envelope or stresswave. The normalized kurtosis is defined as the fourth statistical moment of the signal about the mean of the signal, divided by the fourth power of the standard deviation. The normalized kurtosis detects single peaks in the vibration pattern which are caused by cracks or pitting on one or two teeth on a gear. It is a nondimensional parameter with a value of 3 for a signal with a Gaussian distribution (i.e., a gear in good condition). A normalized kurtosis value of approximately 6 and higher signifies a possible cracked or pitted tooth on the gear being monitored.

\section{$\underline{\text { Test Procedure }}$}

The test gears were run in an offset position with a contact width of $2.8 \mathrm{~mm}$ (0.11 in.) on the $6.35-\mathrm{mm}$ (0.25-in.-) wide gear. This provided a high-contact stress without excessive tooth-bending stress and allowed four surface fatigue tests per set of gears. The tests were run on the NASA Lewis gear test rig shown in Fig. 6. 
All test gears were run-in at a load of $1225 \mathrm{~N} / \mathrm{cm}$ (700 lb/in.) for $1 \mathrm{hr}$. The load was then increased to $5784 \mathrm{~N} / \mathrm{cm}$ (3305 lb/in.) which gives a $1.71 \mathrm{GPa}$ (248 ksi) maximum hertz stress at the tooth pitch line. This load gave a bending stress of $0.26 \mathrm{GPa}$ (37 ksi) when the load was at this pitch point. The gears were operated at $10000 \mathrm{rpm}$ and lubricant was supplied to the inlet mesh at $800 \mathrm{~cm} / \mathrm{min}(0.21 \mathrm{gal} / \mathrm{min})$ at $320 \pm 6 \mathrm{~K}\left(116 \pm 10^{\circ} \mathrm{F}\right)$. The lubricant outlet temperature was nearly constant at $350 \pm 3 \mathrm{~K}\left(170 \pm 5^{\circ} \mathrm{F}\right)$. The tests were run continuously $(24 \mathrm{hr} / \mathrm{day})$ until a failure occurred, or the 500-hr test limit was completed with no failure.

The gear vibration data were taken from an accelerometer mounted on the gearbox shaft-bearing housing, adjacent to the gear mesh. The accelerometer was mounted at a $20^{\circ}$ position on the bearing along the line of action of the gear tooth. A once-per-revolution signal and multiply pulse count (normally several counts per tooth; but for these tests, the multiply pulse was 28 , or one per tooth) were used by the system to determine the various output parameters. Data samples were taken approximately every $\mathbf{5} \mathrm{min}$ for the duration of the test. Plots of one time-synchronous-averaged gear revolution were retained for each 5-min data sample of gear pair stresswave, baseband envelope, and raw baseband. A set of 11 feature plots was developed by the program for each of the three data samples to show different diagnostic parameters from the beginning to the end of the test. These plots include these parameters: raw vibration amplitude; noise, harmonic, nonmesh energy, and peak ratios; peak residual ratios $\mathbf{A}, \mathrm{B}$, and $\mathrm{C}$; kurtosis; peak residual; and total energy. An amplitude limit was set on several of the feature plots to provide a warning when the limit was exceeded. Most of the tests were continued after detection of a failure to determine the effects of further damage on the various diagnostic parameters used in the system.

\section{Results and Discussion}

Several gear surface fatigue tests were conducted with M-50 NiL spur gears. The tests were continued until a surface fatigue failure occurred or the test completed $500 \mathrm{hr}$. If the test completed $500 \mathrm{hr}$ without failure, it was considered complete and was suspended. Portions of the tests in this series were monitored with a contractor-supplied gear vibration diagnostic system in order to detect the occurrence of surface fatigue spalls. In several of the tests, the gears developed fatigue spalls within the 500-hr test time. The diagnostic results of three of these fatigue test failures are presented in this paper.
Figure 7(a) shows plots of the gear pair stresswave and Fig. T(b) shows plots of the gear pair baseband envelope, all from test run $A$. These plots were taken at various intervals during the test. The horizontal scale covers one revolution of the gear and shows the condition of each of the 28 teeth, whereas the vertical scale shows the amplitude of the signal and indicates the intensity of the tooth load. Because of the many vibration modes of the gearbox, the vibration resulting from individual teeth was not as distinct as it would be for a gearbox with a cleaner vibration signal. Figure $7(\mathrm{a})$ shows an increase in amplitude on tooth 2 , which occurred near the end of the test. Figure 9 shows the fatigue spall that caused the increase in vibration amplitude on tooth 2.

Figure 8 displays some of the feature plots that were generated with the data from Fig. 7 and that show the various parameters from the start until the end of test run $A$. The peak residual ratio and kurtosis of the gear pair stresswave are shown in Fig. $8(\mathrm{a})$, and the gear pair baseband envelope in Fig. 8(b). These plots indicate that something was happening approximately halfway through the test; however, there were no indications of a failure in the time-averaged vibration plots. Near the end of the test, these feature plots again show that something was happening. The time-averaged vibration plots show that one tooth on the gear pair was producing a higher than normal dynamic load. Tooth 2 was examined and found to have a sizable fatigue spall, as shown in Fig. 9. The line in the center of the tooth is the unrun portion of the tooth surface between the two offset runs on the tooth flank.

Figure 10, parts (a) and (b), show the plots of the gear pair stresswave and the gear pair baseband envelope, respectively, from test run B. These plots were taken at the beginning of the test and at the end of the 202-hr total test time. At the beginning of the test, all the teeth showed a fairly low amplitude and were about the same except for the effect of rig vibration. Near the end of the test, the gear pair stresswave and gear pair baseband envelope showed an increased amplitude for one tooth (tooth 4) above that of the other teeth.

Figure 11 shows some of the feature plots for the 202-hr run B which were produced by the diagnostic system and generated from the data in Fig. 10. Figure 11 (a) is the peak residual ratio and kurtosis of the gear pair raw baseband. Figure $\mathbf{1 1}(\mathrm{b})$ is the peak residual ratio and kurtosis of the gear pair baseband envelope. These plots indicate that a minor event occurred at approximately 50 percent of the test completed. A second event occurred at approximately 87 percent of the 202-hr test. The time-averaged plots show that one 
tooth (tooth 4) on the gear pair was producing a higher dynamic load. This tooth was found to have fairly sizable fatigue spall, as shown in Fig. 12.

Another M-50 NiL gear test (run C) completed a total of $69 \mathrm{hr}$ and resulted in some fatigue spalls on three teeth. One was a medium size spall; the others had smaller sized pitting. The plots for the time-averaged gear pair stresswave and gear pair baseband envelope are shown in Fig. 13. This figure represents test times of approximately 40,90 , and 100 percent of the $69-\mathrm{hr}$ test time. The plot at 40 percent of test time shows some failure as indicated by an increased amplitude of the vibration near tooth $\mathbf{5}$ for both the gear pair stresswave and baseband envelope. Some indication of failure can also be seen in Fig. 14 at about 40 percent of the total test time. At approximately 90 percent of the test time, there is further indication of failure near tooth 7 and an indication of higher amplitude (shown on the four plots in Fig. 14). Nearer to the end of the test, there was further indication of failure on the tooth vibration plots and features plots probably caused by additional tooth pitting and increased tooth damage on the teeth already pitted.

Figure 15 shows the failed gear teeth from test run C. Three adjacent teeth on this gear have fatigue spalls and another tooth (not shown), four teeth ahead of these, has a fairly large fatigue spall. Several plots of the time-synchronous-averaged signal for this test give some indication of failures on more than one tooth and at the locations where the fatigue spalls occurred on the gear.

From the previous discussion of test results we concluded that the gear diagnostic system used in this test program detected gear tooth fatigue spalls on a regular basis even though the gearbox used for testing had a vibration signal that sometimes masked the gear mesh frequency. This test program also determined that the diagnostic system used for detecting gear fatigue spalls is an effective system for that purpose.

\section{$\underline{\text { Conclusion }}$}

A vibration diagnostic system was used to detect spur gear surface pitting fatigue in a closed-loop gear fa- tigue test rig. The diagnostic system consists of a personal computer with an analog-to-digital conversion board, a diagnostic system unit, and software. The system uses time-synchronous averaging of the vibration signal and produces an image of each tooth on any gear in a transmission. Several data processing methods were used to analyze parameters such as gear pair stresswave and raw baseband vibration images, and the kurtosis and peak residual ratio of those vibration images. The system provides limits for the various parameters and gives a warning when the limits are exceeded. Several spur gear tests were conducted with this system and the vibration data analyzed at 5 -min intervals. The system was able to detect gear tooth fatigue spalls and locate the fatigue spalls on individual gear teeth. The results show that the system is fairly effective at detecting gear fatigue spalls in spur gears operating at $10000 \mathrm{rpm}$ and at 250000 psi hertz stress.

\section{$\underline{\text { References }}$}

1. Reynolds, H.W., Jr., "Turbine Oil and Test Method Development Needed For Current and Future Engines, ${ }^{\text {Proceedings of The USAF-SwRI Turbine }}$ Lubrication Conference, edited by P.M. Ku, Southwest Research Institute, San Antonio, TX, 1967, pp. 43-53.

2. Zakrajsek, J.J., "An Investigation of Gear Mesh

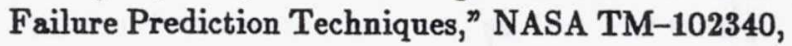
1989.

3. Stewart, R.M., "Some Useful Data Analysis Techniques For Gearbox Diagnostics," Report MHM/R/10/77, Machine Health Monitoring Group, Institute of Sound and Vibration Research, University of Southhampton, England, July 1977.

4. Zakrajsek, J.J., Townsend, D.P., Oswald, F.B., and Decker, H.J., "Analysis and Modification of a Single-Mesh Gear Fatigue Rig for Use in Diagnostic Studies," NASA TM-105416, 1992. 


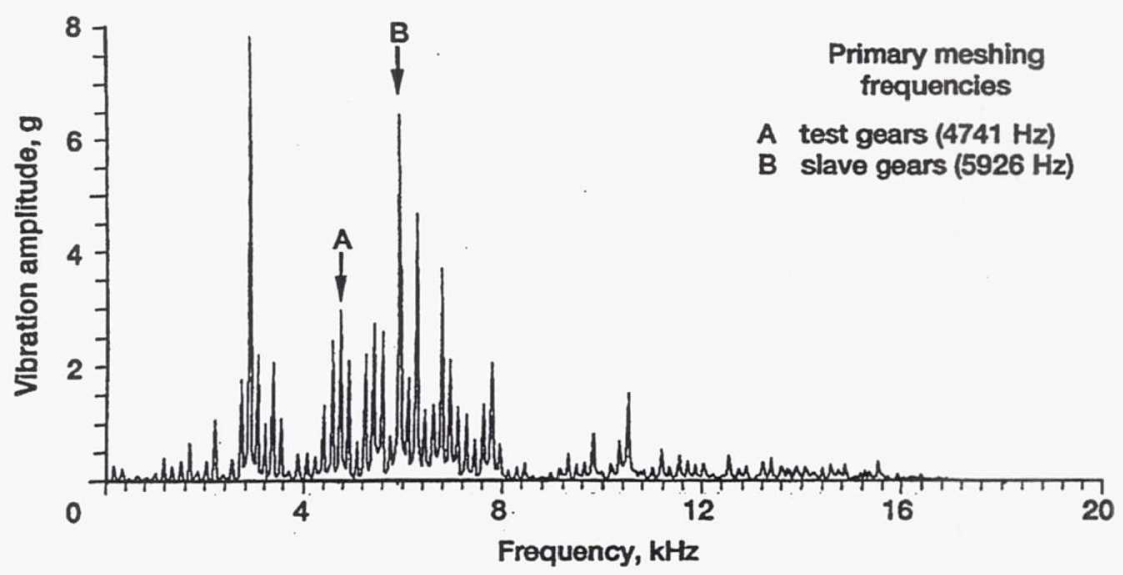

Figure 1.-Typical vibration spectrum from NASA Lewis gear rig.

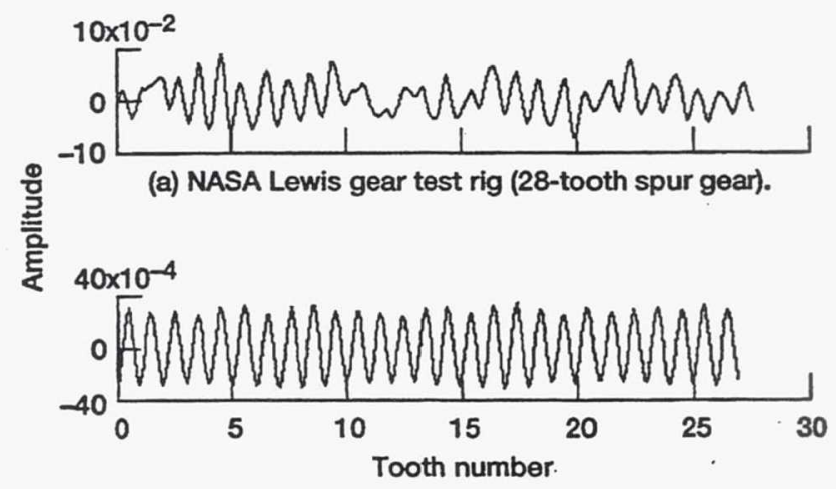

(b) Helicopter gearbox (27-tooth sun gear).

Figure 2.-Typical gear signatures.

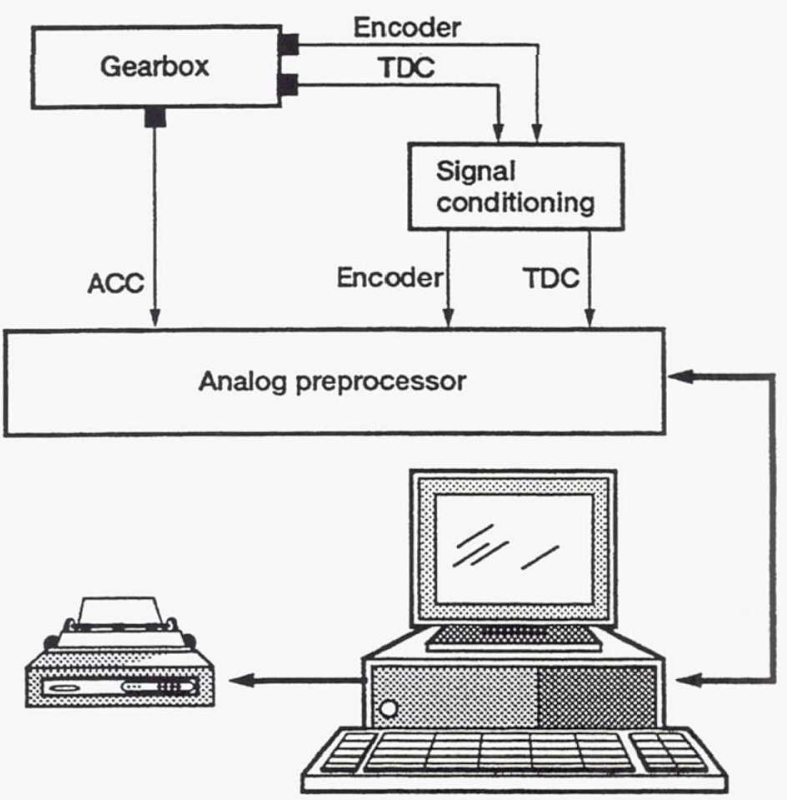

Figure 3.-Gear diagnostic system. 


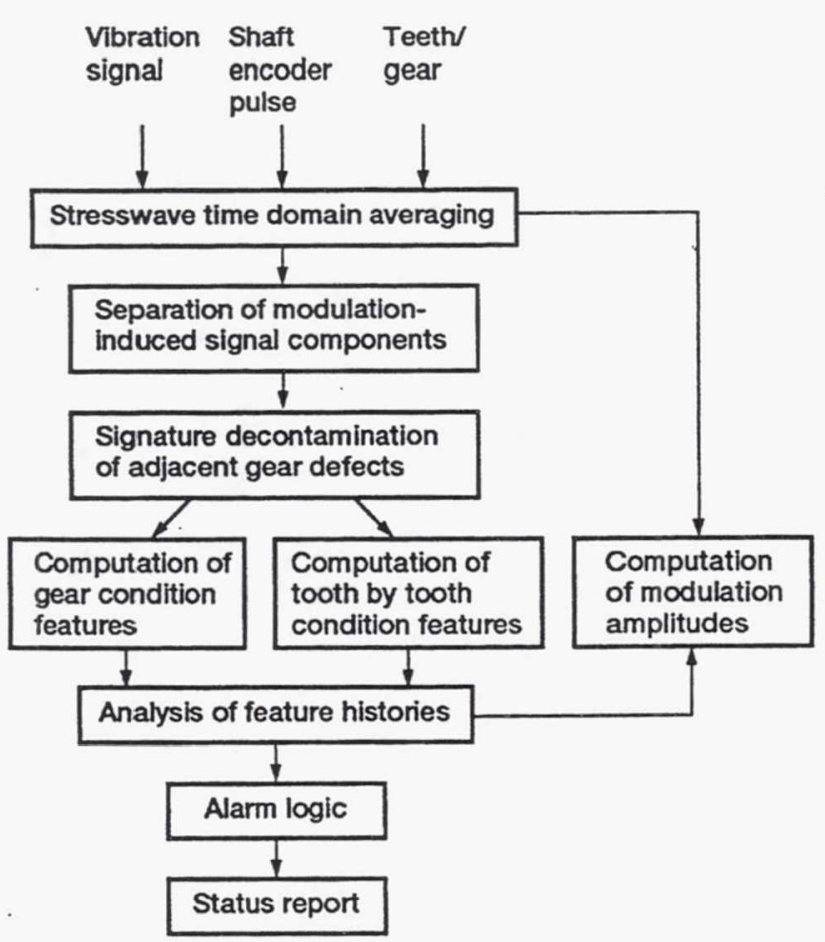

Figure 4.-Gear diagnostic system flowchart.

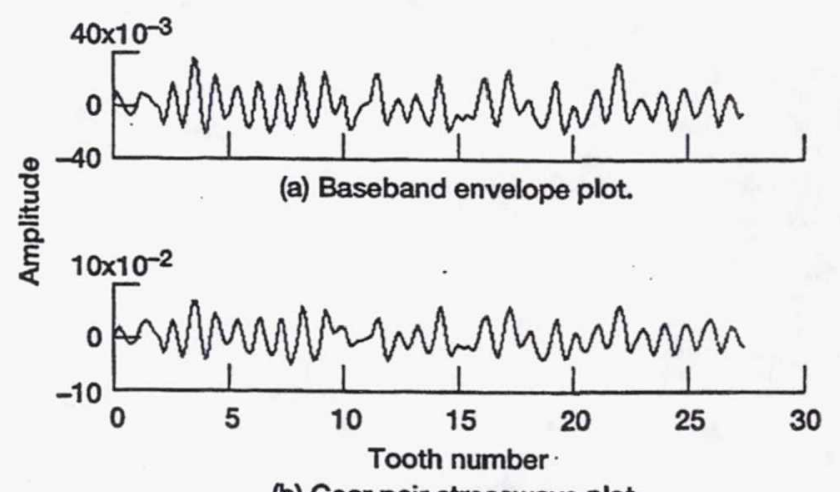

(b) Gear pair stresswave plot.

Figure 5.-Typical vibration patterns for NASA Lewis test rig.

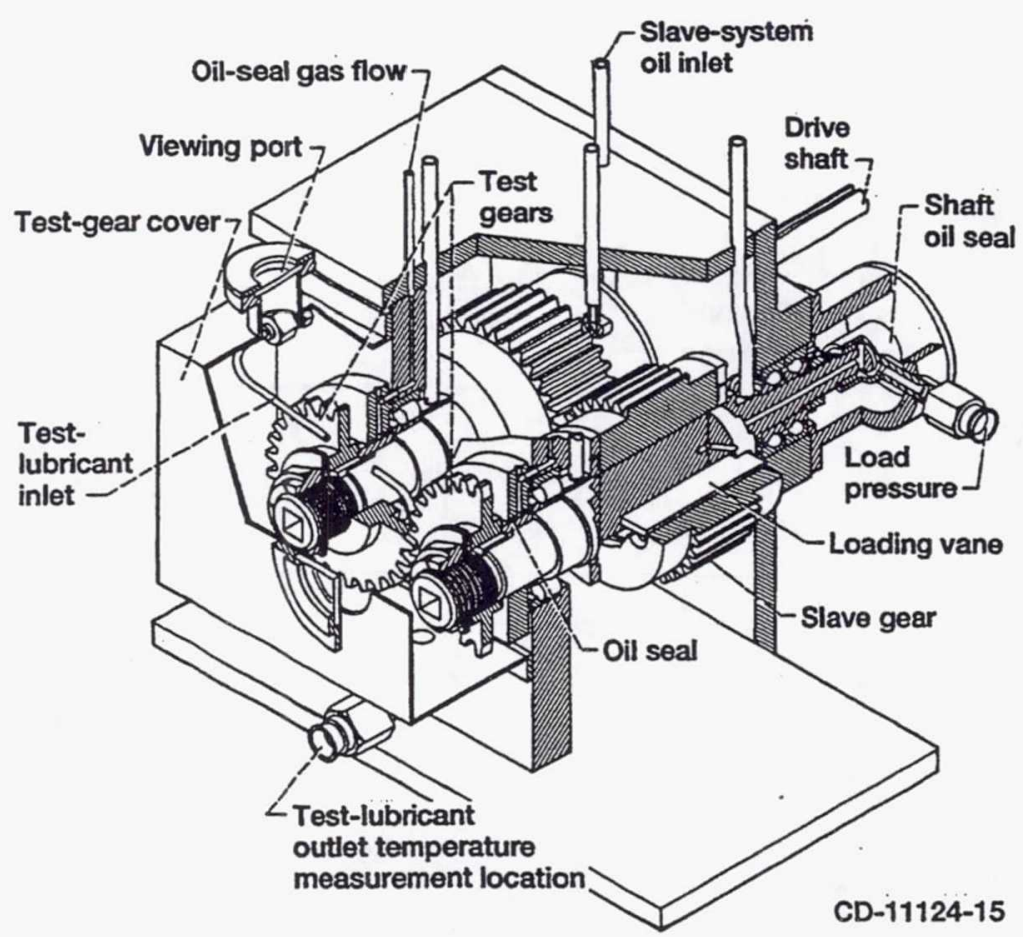

Figure 6.-NASA Lewis gear test rig. 

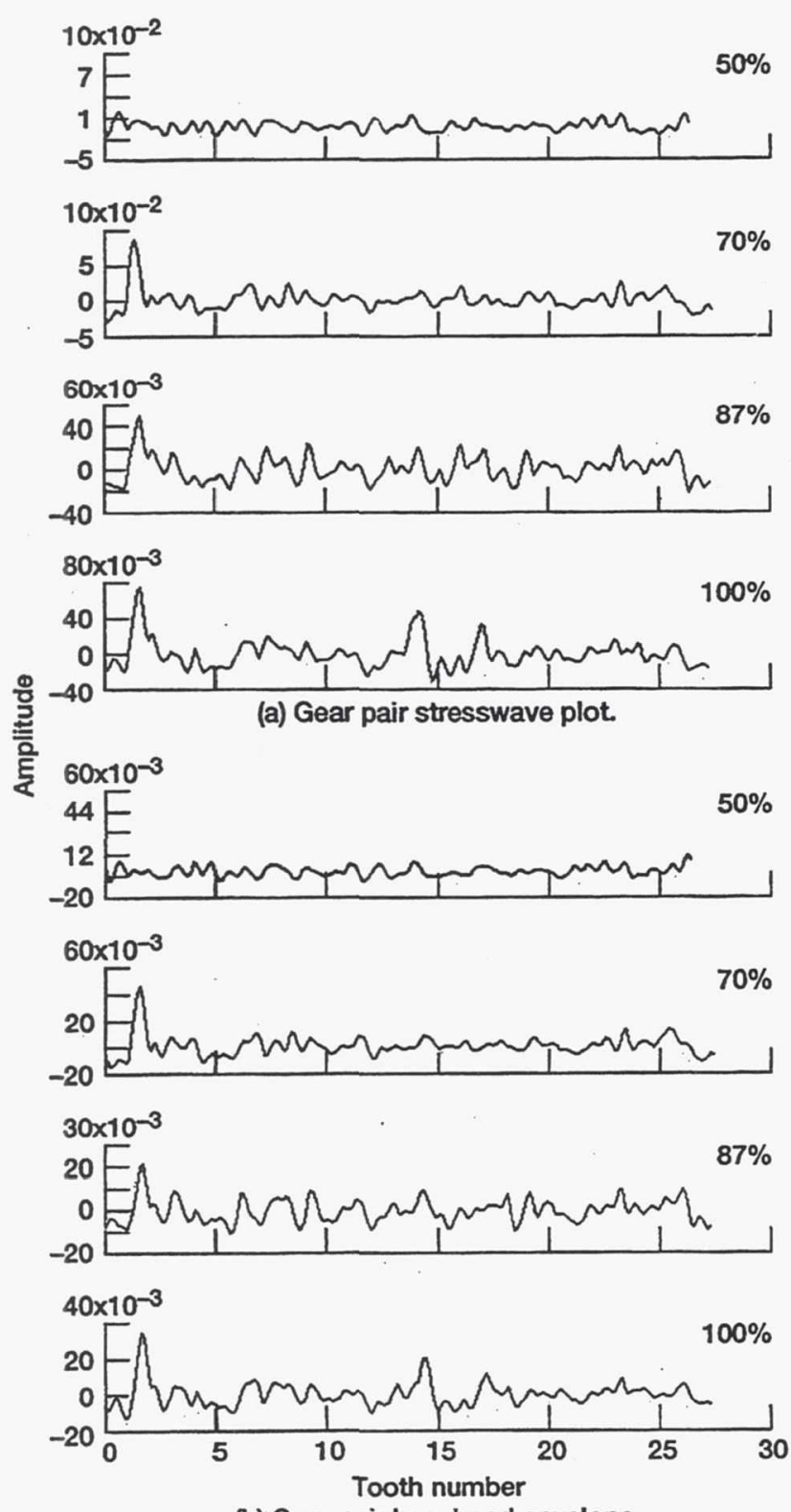

(b) Gear pair baseband envelope.

Figure 7.-Time-synchronous-averaged plots for test run A.
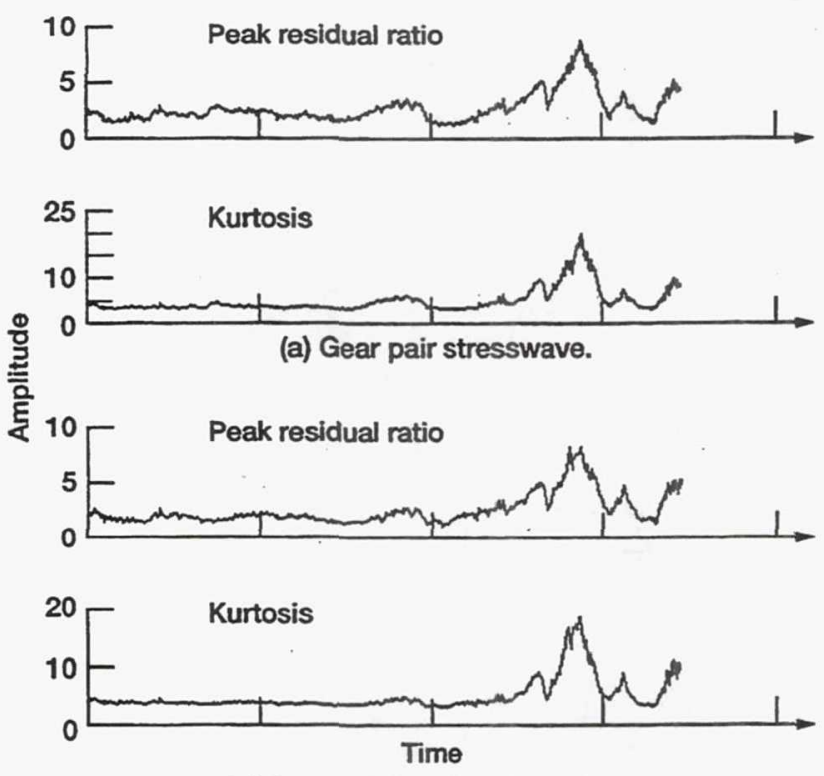

(b) Gear pair baseband envelope.

Figure 8.-Feature plots for test run A.

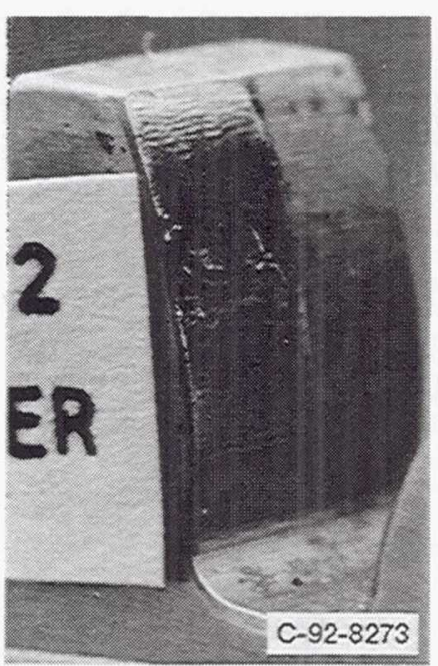

Figure 9.-Gear tooth fatigue spall for test run A. 

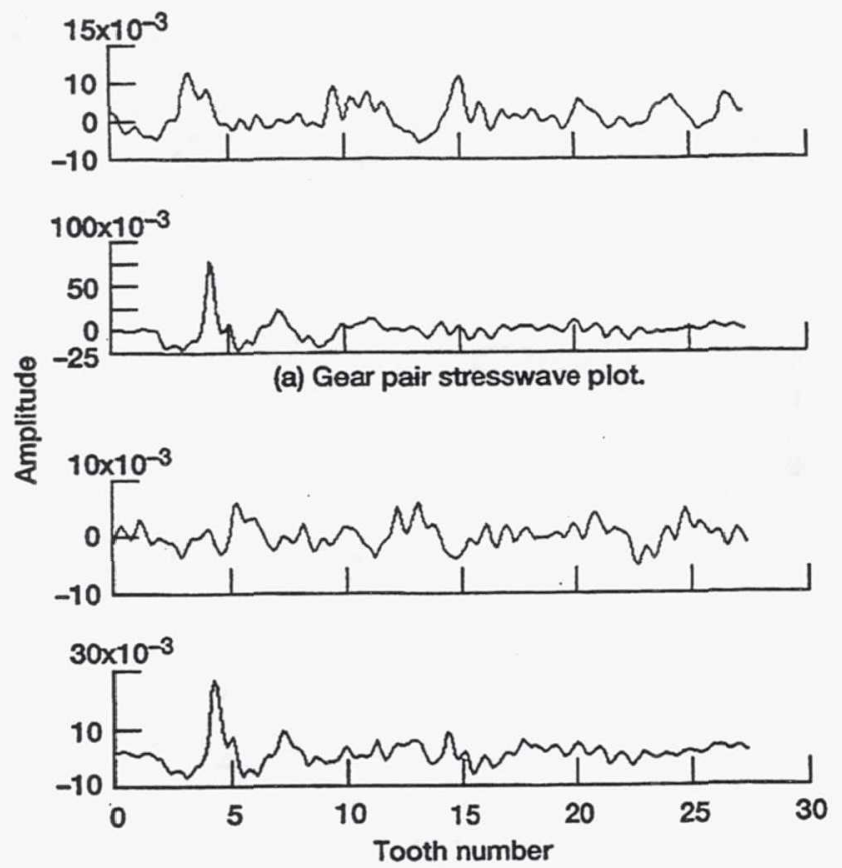

(b) Gear pair baseband envelope.

Figure 10.-Time-synchronous-averaged plots for test run B.

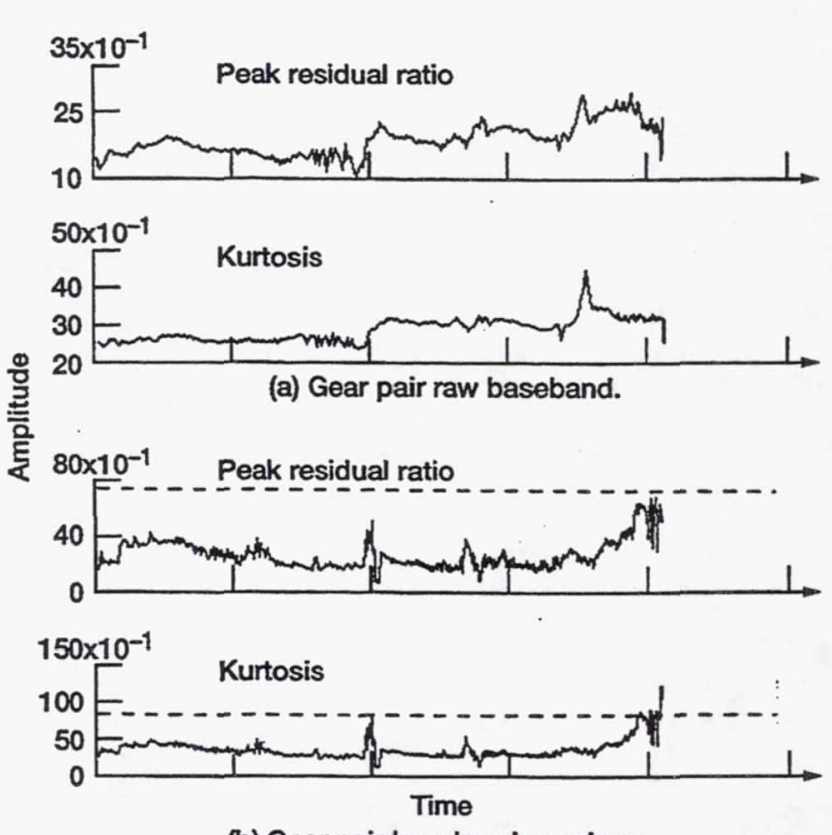

(b) Gear pair baseband envelope.

Figure 11. -Feature plots for test run B.

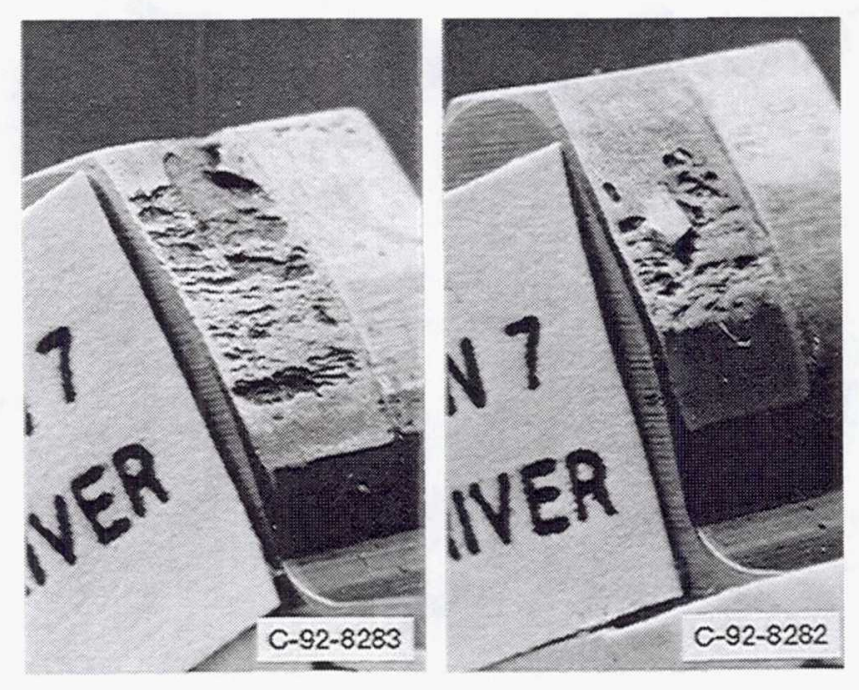

Figure 12.-Gear tooth fatigue spalls for test run B. 
${ }_{-10}^{15 \times 10^{-2}}$

10\%10\%

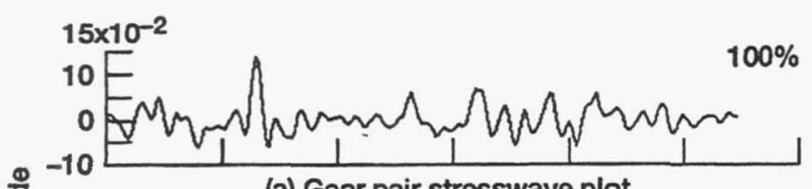

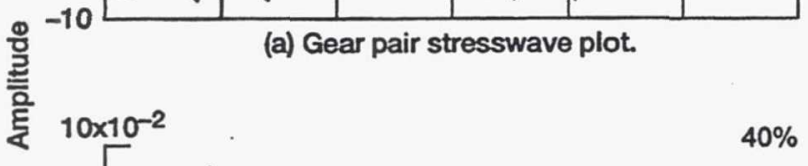

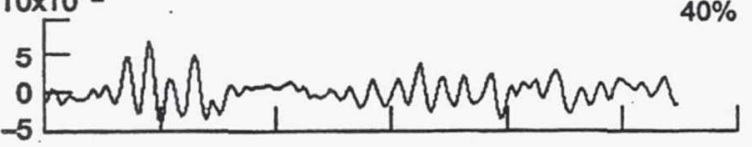
$8 \times 10^{-2} \quad 90 \%$

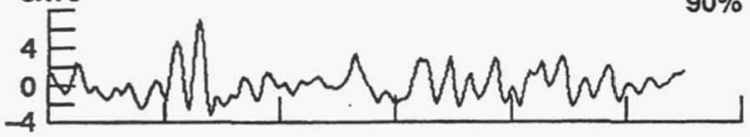
$60 \times 10^{-3} \quad 100 \%$ $\frac{-40}{50} \frac{10,15}{10}{ }_{\text {Tooth number }}^{40}$ (b) Gear pair baseband envelope.

Figure 13.-Time-synchronous-averaged plots for test run C.
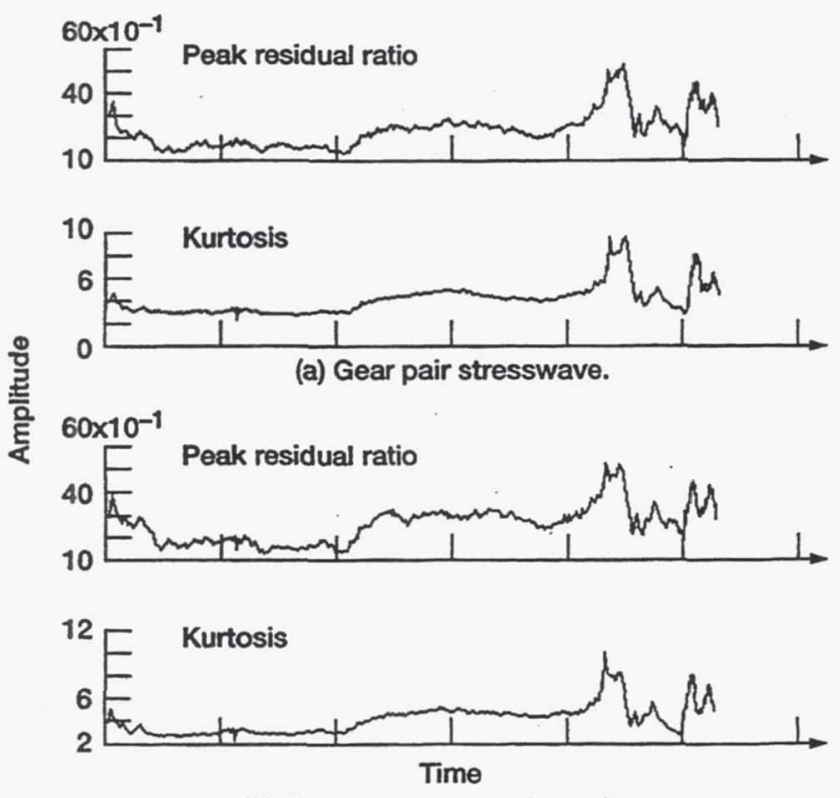

(b) Gear pair baseband envelope.

Figure 14.-Feature plots for test run C.
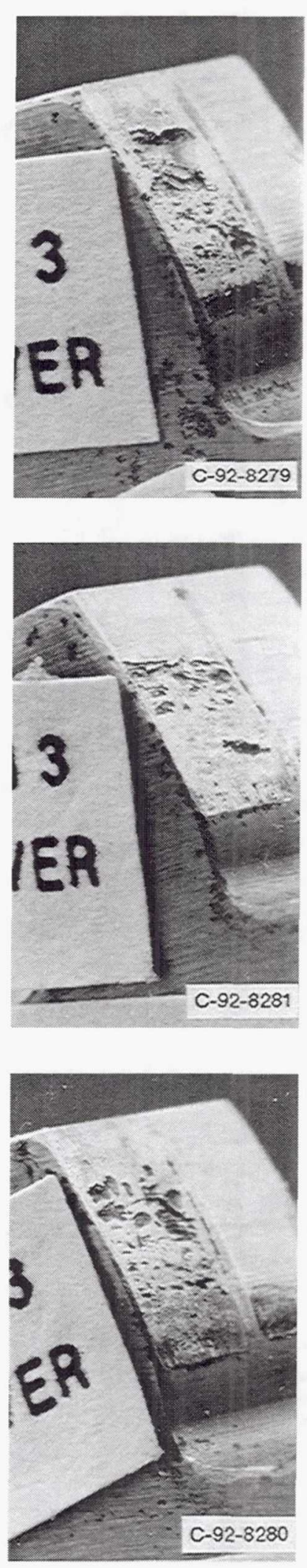

Figure 15.-Gear tooth fatigue spall for test run C. 
Public reporting burden for this collection of information is estimated to average 1 hour per response, including the time for reviewing instructions, searching existing data sources, gathering and maintaining the data needed, and completing and reviewing the collection of information. Send comments regarding this burden estimate or any other aspect of this collection of information, including suggestions for reducing this burden, to Washington Headquarters Services, Directorate for Information Operations and Reports, 1215 Jefferson Davis Highway, Suite 1204, Arlington, VA 22202-4302, and to the Office of Management and Budget, Paperwork Reduction Project (0704-0188), Washington, DC 20503.

\begin{tabular}{|l|l|l|}
\hline $\begin{array}{c}\text { 1. AGENCY USE ONLY (Leave blank) } \\
\text { 2. REPORT DATE } \\
\text { June } 1993\end{array}$ & $\begin{array}{r}\text { 3. REPORT TYPE AND DATES COVERED } \\
\text { Technical Memorandum }\end{array}$ \\
\hline
\end{tabular}

\section{TITLE AND SUBTITLE}

Evaluation of a Vibration Diagnostic System for the Detection of Spur Gear Pitting Failures

6. AUTHOR(S)

Dennis P. Townsend and James J. Zakrajsek
5. FUNDING NUMBERS

WU-505-62-10

1L162211A47A

7. PERFORMING ORGANIZATION NAME(S) AND ADDRESS(ES)

NASA Lewis Research Center

Cleveland, Ohio 44135-3191

and

Vehicle Propulsion Directorate

U.S. Army Research Laboratory

Cleveland, Ohio 44135-3191

9. SPONSORING/MONITORING AGENCY NAME(S) AND ADDRESS(ES)

National Aeronautics and Space Administration

Washington, D.C. 20546-0001

and

U.S. Army Research Laboratory

Adelphi, Maryland 20783-1145

8. PERFORMING ORGANIZATION REPORT NUMBER

E-7752

10. SPONSORING/MONITORING AGENCY REPORT NUMBER

NASA TM-106103

AIAA-93-2298

ARL-TR-11

11. SUPPLEMENTARY NOTES

Prepared for the 29th Joint Propulsion Conference and Exhibit cosponsored by the ALAA, SAE, ASME, and ASEE, Monterey, California, June 28-30, 1993. Dennis P. Townsend and James J. Zakrajsek, NASA Lewis Research Center. Responsible person, Dennis P. Townsend, (216) 433-3955.

12a. DISTRIBUTION/AVAILABILITY STATEMENT

12b. DISTRIBUTION CODE

Unclassified - Unlimited

Subject Category 37

\section{ABSTRACT (Maximum 200 words)}

A vibration diagnostic system was used to detect spur gear surface pitting fatigue in a closed-loop spur gear fatigue test rig. The diagnostic system, comprising a personal computer with an analog-to-digital conversion board, a diagnostic system unit, and software, uses time-synchronous averaging of the vibration signal to produce a vibration image of each tooth on any gear in a transmission. Several parameters were analyzed including gear pair stresswave and raw baseband vibration, kurtosis, peak ratios, and others. The system provides limits for the various parameters and gives a warning when the limits are exceeded. Several spur gear tests were conducted with this system and vibration data analyzed at 5 -min. intervals. The results presented herein show that the system is fairly effective at detecting spur gear tooth surface fatigue pitting failures.

\section{SUBJECT TERMS}

Bearings; Fatigue; Diagnostic gear

\begin{tabular}{|c|c|c|}
\hline $\begin{array}{c}\text { 17. SECURITY CLASSIFICATION } \\
\text { OF REPORT } \\
\text { Unclassified }\end{array}$ & $\begin{array}{c}\text { 18. SECURITY CLASSIFICATION } \\
\text { OF THIS PAGE } \\
\text { Unclassified }\end{array}$ & $\begin{array}{c}\text { 19. SECURITY CLASSIFICATION } \\
\text { OF ABSTRACT } \\
\text { Unclassified }\end{array}$ \\
\hline
\end{tabular}

